\title{
OS REFLEXOS DA EVOLUÇÃO TECNOLÓGICA NO ÂMBITO TRIBUTÁRIO: A EXTENSÃO DA IMUNIDADE TRIBUTÁRIA AOS LIVROS ELETRÔNICOS E AOS MEIOS MAGNÉTICOS
}

\section{THE CONSEQUENCES OF TECHNOLOGICAL DEVELOPMENTS IN TAX SCOPE : IMMUNITY EXTENSION OF TAX TO ELECTRONIC BOOKS AND MAGNETIC MEDIA}

\author{
${ }^{1}$ Raysa Natiene de Araújo Rodrigues Campos \\ ${ }^{2}$ Bruno Bastos De Oliveira
}

\begin{abstract}
RESUMO
O poder de tributar encontra limites na própria Magna Carta ao estabelecer, em seu âmago, princípios e imunidades tributárias que são de observância obrigatória pelos entes federados quando da criação do tributo previsto in abstrato. Ocorre que, com a crescente e inevitável evolução tecnológica o conceito de livro transcende a ideia de algo palpável, material, pois a informação pode ser produzida em outros suportes físicos diferentes do papel, como os meios magnéticos. Assim, o presente artigo terá como foco a possibilidade de extensão ou não da referida imunidade tributária aos livros eletrônicos.
\end{abstract}

Palavras-chave: Evolução tecnológica, Imunidade, Livro eletrônico

\begin{abstract}
The taxing power finds limits in the very Constitution to establish, at its core, principles and tax immunities that are obligatory by federal agencies when setting the tax provided for in the abstract. It happens that, with increasing and inevitable technological developments book concept idea transcends palpable, material, because information can be produced in different physical media other than paper, such as magnetic media. Thus, this article will focus on the possibility of extension or not of that tax immunity to electronic books
\end{abstract}

Keywords: Technological evolution, Immunity, Electronic book

\footnotetext{
${ }^{1}$ Especialista em Direito Tributário e Processo Tributário pela Escola Superior de Advocacia Flósculo da Nóbrega - ESA PB, (Brasl). Servidora Pública (cargo técnico-administrativo) da Universidade Estadual da Paraíba, UEPB - PB, (Brasil). E-mail: raysanatiene@hotmail.com

${ }^{2}$ Professor e Doutorando em Ciências Jurídicas pela Universidade Federal da Paraíba, UFPB - PB, (Brasil). E-mail : bbastos.adv@gmail.com
} 


\section{INTRODUÇÃO}

A Constituição Federal de 1988 tem como fundamento basilar a dignidade da pessoa humana e, em razão disso, elenca, em seu arcabouço, direitos e garantias individuais com o fim precípuo de assegurar aos cidadãos uma proteção efetiva em face do Poder Estatal.

Dentre os poderes que dispõe o Estado está o de tributar, poder este que se mostra de suma importância na medida em que visa arrecadar recursos para realização dos seus fins sociais. Assim, os direitos fundamentais possuem, no âmbito da relação jurídica tributária, dúplice função, pois funcionam como sustentáculos à tributação realizada pelo Estado ao tempo em que também limitam essa atividade.

Tanto é assim que, a Constituição prevê expressamente Princípios e Imunidades Tributárias que se constituem como verdadeiros limites ao poder de tributar com o fim de resguardar o contribuinte contra qualquer ação estatal que exceda ou abuse de sua competência tributária, juridicamente delimitada na própria Magna Carta.

As imunidades tributárias relativas especificamente aos impostos, previstas no art.

150, inciso VI da CF, são normas que implicam na impossibilidade de o ente federado instituir impostos sobre determinadas matérias, não sendo possível, sequer a criação do tributo in abstrato, caracterizando-se, assim, como um direito subjetivo das pessoas favorecidas em não serem tributadas.

No presente artigo, iremos nos debruçar, de forma mais detida, a hipótese de imunidade prevista na alínea "d" do mencionado inciso, que se refere aos livros, jornais, periódicos e o papel destinado a sua impressão.

A imunidade em tela tem o escopo de cumprir os mandamentos constitucionais pertinentes aos direitos fundamentais previstos no art. $5^{\circ}$, quais sejam: liberdade de expressão, artística e a disseminação da cultura.

Ocorre que, com a crescente e inevitável evolução tecnológica o conceito de livro transcende a ideia de algo palpável, material, pois a informação pode ser produzida/armazenada em outros suportes físicos diferentes do papel, como os meios magnéticos, motivo pelo qual se faz necessária uma releitura do conceito jurídico de livro, bem como dos seus suportes físicos, a luz da nova realidade social, visto que os instrumentos utilizados para visualização do livro eletrônico possuem a mesma 
finalidade do papel, não havendo, assim, qualquer diferença quanto ao conteúdo, mas tão somente quanto a base física que exterioriza e acondiciona a informação.

Nesse sentido, serão abordadas as divergentes correntes doutrinárias acerca da possibilidade de extensão ou não da imunidade em tela aos livros eletrônicos, assim como aos seus respectivos suportes, com ênfase nos entendimentos da nossa Corte Suprema e nas recentes decisões dos Tribunais pátrios inferiores, sempre tendo como fio condutor a perspectiva de concretização do ideal de cidadania tributária.

É justamente a partir da análise de como o sistema tributário de determinado Estado se apresenta que, limitando-se o objeto de estudo ao sistema tributário brasileiro, se torna necessário a consecução de observação menos formal e mais profunda, buscando responder basicamente a seguinte questão: a partir desse sistema tributário posto, inclusive no que concerte à questão das imunidades tributárias, é possível se falar e concretização de cidadania tributária? É a busca por essa resposta que norteará o presente trabalho.

\section{IMUNIDADE TRIBUTÁRIA: ASPECTOS PROPEDÊUTICOS}

A Magna Carta com o escopo de regular a ação estatal de criar tributos e, sobretudo, resguardar o cidadão contra eventuais abusos de poder trouxe em seu âmago Princípios e Imunidades Tributárias como limitadores do poder de tributar que “exprimem-se em forma de vedações constitucionais às entidades tributantes" (SILVA, 2001, p.691).

Esse poder tributário é dividido entre a União, os Estados, o Distrito Federal e os Municípios, estando delimitado juridicamente pela Constituição, na forma de competências tributárias, com a devida previsão in abstrato do tributo a ser instituído por cada ente federativo.

Se de um lado trouxe a Constituição à previsão da possibilidade de instituição de tributos pelos entes federados, doutra banda elencou regras imunizantes que "fixam, por assim dizer, a incompetência das entidades tributantes para onerar, com exações, certas pessoas, seja em função de sua natureza jurídica, sejam porque coligadas a determinados fatos, bens ou situações”. (CARRAZA, 2011, p. 772)

Comunga desse entendimento OLIVEIRA (2010, p.117) ao afirmar que: 


\begin{abstract}
A limitação maior ao poder de tributar reside na ,imunidade ${ }^{e e}$, que, por força da própria Constituição, implica incompetência ou impotência para as pessoas políticas instituírem impostos relativamente a certas matérias. Não há, pois, incidência do tributo, pois as hipóteses alcançadas por tais regras constitucionais colocam-se fora do campo de atuação do tributo, visto que não constituem fato gerador da respectiva obrigação.
\end{abstract}

Destarte, as imunidades tributárias são verdadeiras regras negativas de competência, visto que são hipóteses em que a competência não pode ser exercida pelo ente tributante, afirmando MACHADO (2005, p.282), nesse sentido, que a "imunidade é o obstáculo decorrente da regra da Constituição à incidência de regra jurídica tributária”. Tem, dessa forma, a imunidade natureza dúplice, pois "de um lado exsurge como norma constitucional demarcatória da competência tributária, por continente de hipótese de intributabilidade, e, de outro, constitui direito público subjetivo das pessoas direta ou indiretamente por ela favorecidas." (COSTA, 2009, p.79),

Assim, vê-se cristalinamente que como a regra imunizante constitui-se como verdadeiro limite a competência tributária, está o ente federado impedido de editar leis para definir como hipóteses de incidência as situações do art. 150, inciso VI, elencadas pela Constituição como imunes, quais sejam:

Art. 150. Sem prejuízo de outras garantias asseguradas ao contribuinte, é vedado à União, aos Estados, ao Distrito Federal e aos Municípios:

(...)

VI - instituir impostos sobre:

a) patrimônio, renda ou serviços, uns dos outros;

b) templos de qualquer culto;

c) patrimônio, renda ou serviços dos partidos políticos, inclusive suas fundações, das entidades sindicais dos trabalhadores, das instituições de educação e de assistência social, sem fins lucrativos, atendidos os requisitos da lei;

d) livros, iornais, periódicos e o papel destinado a sua impressão.

e) fonogramas e videofonogramas musicais produzidos no Brasil contendo obras musicais ou literomusicais de autores brasileiros e/ou obras em geral interpretadas por artistas brasileiros bem como os suportes materiais ou arquivos digitais que os contenham, salvo na etapa de replicação industrial de mídias ópticas de leitura a laser. (grifo nosso)

Faz-se necessário salientar, que, além dessas há no corpo da Constituição Federal de 1988 outras regras imunizantes, conforme previsão no art. $5^{\circ}$, inciso XXXIV que garante o direito de petição, bem como a obtenção de certidões em repartições públicas independente do pagamento de taxas e no art. 195, $\S 7^{\circ}$ que traz a imunidade de 
contribuições sociais para as entidades beneficentes de assistência social que atendam as exigências estabelecidas em lei.

Cumpre trazer a diferença entre imunidade tributária e isenção. A imunidade, consoante elucidado, trata de uma regra negativa de competência prevista constitucionalmente, motivo pelo qual a doutrina afirma que a imunidade é hipótese de não incidência tributária constitucionalmente qualificada, de modo que jamais haverá uma hipótese de imunidade fora da Carta Magna, elucidando, assim, SILVA (2002, p.697) que "as imunidades configuram privilégios de natureza constitucional e não podem estender-se além das hipóteses expressamente previstas na Constituição".

Já a isenção, por outro lado, por se tratar de uma benesse fiscal, tem previsão infraconstitucional, sendo assim uma hipótese de não incidência legalmente qualificada. Nesse diapasão, afirma MACHADO (2005, p.232) que

\begin{abstract}
o que distingue, em essência, a isenção da imunidade é a posição desta última em plano hierárquico superior. Daí decorrem consequências da maior importância, tendo-se em vista que a imunidade, exatamente porque estabelecida em norma residente na Constituição, corporifica princípio superior do ordenamento jurídico (...)
\end{abstract}

Portanto, percebe-se que as regras imunizantes possuem como finalidade precípua assegurar os direitos e garantias individuais do cidadão, previstos no art. $5^{\circ}$ da Magna Carta, motivo pelo qual infere-se que as imunidades transcendem o âmbito do direito tributário, privilegiando, por consequência, valores implícitos contemplados pelo constituinte.

\title{
3 Imunidade tributária de livros jornais e periódicos e os papéis destinados a sua impressão
}

A imunidade tributária dos livros eletrônicos perpassa pela exegese do art. 150, VI, "d" da Constituição Federal, no que tange a possibilidade ou não de sua extensão, visto que apresenta como imunes apenas os livros, jornais, periódicos e os papéis destinados a sua impressão.

Inicialmente, deve-se elucidar que essa imunidade tem como escopo cumprir os mandamentos constitucionais pertinentes aos direitos fundamentais previstos no art. $5^{\circ}$, 
incisos VI, IX e XIV, quais sejam, liberdade de expressão, artística e a disseminação da cultura.

Nesse diapasão, preceitua MACHADO $(2005,288)$ que "a imunidade do livro, jornal ou periódico, e do papel destinado a sua impressão, há se ser entendida em seu sentido finalístico", sendo cristalino, assim, que a mens legis objetiva garantir a difusão da cultura e da educação, bem como a assegurar a liberdade de expressão e a manifestação do pensamento.

No que tange ao conteúdo da obra para fins de aplicação ou não da regra imunizante, o entendimento já está sedimentado na nossa Suprema Corte, cujo leading case foi julgado em 25/05/2004, tendo como relatora a Ministra Ellen Gracie, no RE 221. 239/SP, que afirmou que o conteúdo da obra é irrelevante, não cabendo ao intérprete fazer um juízo de valor acerca da qualidade cultural da publicação, senão vejamos:

CONSTITUCIONAL. TRIBUTÁRIO. IMUNIDADE. ART. 150, VI, D DA CF/88. "ÁlBUM DE FIGURINHAS". ADMISSIBILIDADE. 1. A imunidade tributária sobre livros, jornais, periódicos e o papel destinado à sua impressão tem por escopo evitar embaraços ao exercício da liberdade de expressão intelectual, artística, científica e de comunicação, bem como facilitar o acesso da população à cultura, à informação e à educação. 2 . $\mathrm{O}$ Constituinte, ao instituir esta benesse, não fez ressalvas quanto ao valor artístico ou didático, à relevância das informações divulgadas ou à qualidade cultural de uma publicação. $\underline{3}$. Não cabe ao aplicador da norma constitucional em tela afastar este benefício fiscal instituído para proteger direito tão importante ao exercício da democracia, por força de um juízo subjetivo acerca da qualidade cultural ou do valor pedagógico de uma publicação destinada ao público infanto-juvenil. 4. Recurso extraordinário conhecido e provido. (STF - RE: 221239 SP , Relator: ELLEN GRACIE, Data de Julgamento: 25/05/2004, Segunda Turma, Data de Publicação: DJ 06-08-2004 PP-00061 EMENT VOL-02158-03 PP-00597 RTJ VOL-00193-01 PP-00406) (grifo nosso)

No entanto, a discussão se arrobusta quando se tenta estender a referida imunidade a outros insumos além do papel, partindo de um conceito amplo de livro. Dentre os insumos, algumas situações já se mostram pacificadas, conforme pode ser observada na Súmula 657 do Supremo Tribunal Federal, aprovada em 2003, que dispõe que "a imunidade prevista no art. 150, VI, "d", da constituição federal abrange os filmes e papéis fotográficos necessários à publicação de jornais e periódicos”.

Ademais, em 2011, no julgamento do RE 202.149/RS, o STF entendeu que a imunidade tributária no que diz respeito aos insumos é ampla, sendo a referência ao 
papel meramente exemplificativa e não exaustiva abrangendo, dessa forma, produtos e maquinários, senão vejamos:

CONSTITUIÇÃO FEDERAL. Extraia-se da Constituição Federal, em interpretação teleológica e integrativa, a maior concretude possível. IMUNIDADE - "LIVROS, JORNAIS, PERIÓDICOS E O PAPEL DESTINADO A SUA IMPRESSÃO" - ARTIGO 150, INCISO VI, ALÍNEA "D", DA CARTA DA REPUBLICA - INTELIGÊNCIA. A imunidade tributária relativa a livros, iornais e periódicos é ampla, total, apanhando produto, maquinário e insumos. A referência, no preceito, a papel é exemplificativa e não exaustiva. (STF - RE: 202149/ RS , Relator: Min. MENEZES DIREITO, Data de Julgamento: 26/04/2011, Primeira Turma, Data de Publicação: DJe-195 DIVULG 10-10-2011) (Grifo nosso).

Ocorre que, após a referida decisão foi interposto embargos de divergência em que o Ministro Celso de Mello reformou o posicionamento anterior, afirmando que, na Suprema Corte, é pacífica a utilização da interpretação restritiva quanto à imunidade tributária dos insumos, alterando, por sua vez, o entendimento quanto à possibilidade de imunização das chapas de impressão para os jornais. Segue, nesse sentido, um recorte da decisão:

\footnotetext{
Considero, por isso mesmo, que o postulado da imunidade qualifica-se como instrumento de proteção constitucional vocacionado a preservar direitos fundamentais - como a liberdade de informar e o direito do cidadão de ser informado -, em ordem a evitar uma situação de perigosa submissão tributária das empresas jornalísticas (reais destinatárias dessa especial prerrogativa de ordem jurídica), ao poder impositivo do Estado. Ocorre. no entanto, tal como anteriormente assinalei. que o Supremo Tribunal Federal, ao interpretar o alcance e a abrangência da cláusula inscrita no ar t. 150. VI. "d". da Consti tui c ão. fi r mou or i e ntac ão a pr opósi to d a controvérsia ora em julgamento, no sentido de excluir, do âmbito do instituto da imunidade tributária, itens ou insumos outros, além dos expressamente referidos e daqueles que se revelam assimiláveis ao papel. procedendo a uma verdadeira interpretação restritiva do preceito constitucional em referência (STF. Embargos de Divergência no RE: 202149 RS , Relator: Min. CELSO DE MELLO, Data de Julgamento: 14/04/2015, Decisão monocrática, Data de Publicação: DJe-16/04/2015.) (grifo nosso)
}

Assim, vê-se que, em recentíssima decisão, a tendência da nossa Suprema Corte é atribuir uma interpretação restritiva, no que concerne a imunidade dos livros, jornais e periódicos e os seus respectivos insumos de modo a excluir qualquer outro que não seja o papel ou seu similar.

Desse modo, quando se apercebe que a evolução tecnológica coloca ao nosso alcance um leque de recursos imateriais, de caráter científico ou cultural, observa-se que a matéria referente à imunidade dos livros eletrônicos e seus insumos se torna 
sobremaneira polêmica e controvertida, principalmente porque, em que pese ter a nossa Corte Suprema, em 2012, entendido que a imunidade de livro eletrônico é tema de repercussão geral, ainda não há um posicionamento final a respeito, pacificando a temática.

No RE 330817/RJ em que foi reconhecida a referida repercussão geral, o Ministro Relator Dias Toffoli traz as seguintes correntes hermenêuticas acerca da possibilidade ou não de abrangência, vejamos:

\begin{abstract}
A controvérsia acerca da subsunção dos novos meios de comunicação à norma imunizante é objeto de acalorado debate na doutrina e na jurisprudência, sendo inegável a repercussão econômica que dela pode advir, tendo em visa que a extensão do favor constitucional a um novo e expressivo contingente de bens pode causar considerável impacto no erário. No âmbito jurídico, a controvérsia repousa na dicotomia atualmente existente na hermenêutica quanto à interpretação do art. 150, inciso VI, alínea d, da Constituição Federal. Dependendo da corrente hermenêutica adotada, se restritiva ou extensiva, o dispositivo terá essa ou aquela interpretação. A corrente restritiva possui um forte viés literal e concebe que a imunidade alcança somente aquilo que puder ser compreendido dentro da expressão papel destinado a sua impressão. (...) Em contraposição à corrente restritiva, os partidários da corrente extensiva sustentam que, segundo uma interpretação sistemática e teleológica do texto constitucional, a imunidade serviria para se conferir efetividade aos princípios da livre manifestação do pensamento e da livre expressão da atividade intelectual, artística, científica ou de comunicação, o que, em última análise, revelaria a intenção do legislador constituinte em difundir o livre acesso à cultura e à informação. (STF, Plenário, Repercussão Geral no RE $\mathrm{n}^{\circ}$ 330.817, Ministro Relator Dias Toffoli, DJe 28.09.2012) (grifo nosso).
\end{abstract}

Aliás, em precedentes antigos, o STF ao negar a imunidade para livro eletrônico se utilizou de uma interpretação histórica afirmando que o constituinte de 1988 debateu o tema à época, mas não quis inserir outras formas de livros que não os impressos, motivo pelo qual não cabe ao interprete fazê-lo.

Vê-se, desse modo, ante a crescente evolução tecnológica e a disseminação da informação por meio de inúmeros instrumentos eletrônicos, torna-se imperiosa e impostergável a análise da questão de modo a atribuir uma nova roupagem a essa regra imunizante, no que diz respeito a sua abrangência, posto que o nosso ordenamento precisa se coadunar com a dinamicidade social.

Nesse sentido, afirma KFOURI JR. (2010, p. 114) que “a constituição é um conjunto de princípios, que estabelecem um meio para se chegar aos resultados desejados por uma sociedade". 
Em virtude do exposto, percebe-se que a abrangência ou não da imunidade inscrita no art. 150, VI, d, exige uma análise minudente do que deve ser entendido por livro, assim como seu respectivo insumo, para só então chegarmos a uma posição quanto à situação do livro eletrônico e dos meios magnéticos no nosso ordenamento, sendo isso o que se passa a fazer.

\section{A aplicação da imunidade tributária ao livro eletrônico e aos meios magnéticos}

A Lei $n^{\circ} 10.753 / 2003$ que instituiu a Política Nacional do Livro, em seu art. $2^{\circ}$ traz a seguinte definição:

Art. $2^{\circ}$ - Considera-se livro, para efeitos desta Lei, a publicação de textos escritos em fichas ou folhas, não periódica, grampeada, colada ou costurada, em volume cartonado, encadernado ou em brochura, em capas avulsas, em qualquer formato e acabamento.

Observa-se, assim, que o livro está vinculado a um aspecto material, motivo pelo qual necessita-se de uma quebra de paradigma para só então, sanarmos o impasse relativo a interpretação do conceito jurídico de livro, sobretudo quando o seu conteúdo é veiculado por outro meio que não seja o papel ou material similar.

Isso se dá em razão da constante evolução tecnológica que traz a reboque os mais variados instrumentos eletrônicos que também são utilizados para leitura de obras, notícias ou quaisquer outras informações, tendo, inclusive, hodiernamente, diversas livrarias virtuais que somente comercializam seus livros na modalidade ebook.

Os livros eletrônicos são arquivos lidos por meio de softwares veiculados em uma mídia eletrônica, necessitando para tanto de um computador. Além disso, podem ser adquiridos através de simples download em que o livro é retirado de um banco de dados da rede mundial de computadores e transportado para o computador de quem executa a operação. Além disso, pode o livro ter como suporte físico CD, CD-ROM, DVD, kindle, ou outras formas mais modernas como tablets, celulares com a plataforma android, iphones, ipads dentre outros.

Destarte, os instrumentos utilizados para visualização do livro eletrônico tem o mesmo escopo do papel, não havendo, assim, qualquer diferença quanto ao conteúdo, mas tão somente quanto à base física que exterioriza e acondiciona a informação. Tanto é assim que, nesse diapasão, elucida o douto CARRAZA (2011, p. 864): 
Portanto, neste contexto, a palavra livros há de ser entendida em sentido lato. São considerados livros não apenas os tradicionais feitos de papel, mas, também, os seus sucedâneos. Considerem-se ,sucedâneos dos livros ${ }^{\text {ee }}$, para fim de imunidade, todos os objetos da espécie, que contém os textos dos livros, em sua forma corriqueira.

Em que pese à necessidade de atribuir ao livro um sentido lato com a devida equivalência de tratamento dos suportes físicos, ainda não há consenso doutrinário. Parte da doutrina adota uma regra de hermenêutica restritiva afirmando que a imunidade prevista no art. 150, VI, "d" da CF deve ser interpretada de forma literal devendo ser considerado imune somente o papel e outros suportes similares. Nesse sentido, elucida COSTA (2009, p. 100):

Parte da doutrina sustenta que somente o livro feito de papel é imune a impostos, à vista da cláusula ,e o papel destinado a sua impressão ${ }^{\text {e }}$, contida no art. 150, VI, d. Desse modo, estender-se a exoneracão constitucional a outros meios de divulgacão de ideias seria ampliar o querer constitucional, para abranger itens por ela não cogitados. (Grifo nosso)

Essa regra hermenêutica não se coaduna com a concepção moderna de interpretação em que o intérprete tem papel ativo na formação da norma, não sendo um ser neutro, passivo posto que sofre influência de diversos fatores, principalmente, no que tange a avaliação dos fatos sociais e suas consequências, sendo a norma, dessa forma, o resultado da interpretação da literalidade do texto.

Nesse diapasão, afirmou o eminente ex-ministro Eros Roberto Grau (2002, p. 69/70):

$\underline{\text { O sentido expressado pelo texto já é algo novo, distinto do texto. É a norma. }}$ (...) Isso significa que o texto normativo, visando à solução de conflitos (isto é, uma decisão normativamente fundada para problemas práticos, em razão do quê consubstancia dever-ser - sollen, e não sein -, e não contemplação estética), reclama um intérprete (primeiro intérprete) que compreenda e reproduza, não para que um segundo intérprete possa compreender, mas a fim de que um determinado conflito seja decidido. (...) $\underline{\mathbf{A}}$ interpretacão do direito opera a mediacão entre o caráter geral do texto normativo e sua aplicacão particular: isto é. opera a sua insercão na vida. (grifo nosso)

Assim, deve o intérprete fazer uso de métodos hermenêuticos que consigam, a luz da realidade social, efetivar a norma constitucional, de modo a atribuir a Constituição a máxima efetividade possível. Partindo dessas premissas, percebe-se que, ante a crescente e inevitável evolução tecnológica, precisa-se interpretar a imunidade do art. 150, VI, "d" da CF de forma extensiva de modo a alargar o alcance e o sentido da imunidade em tela, pois é o livro um meio de transmissão de informações, 
dedisseminação da cultura não devendo haver qualquer diferença quanto ao tratamento em virtude do suporte físico, pois o que deve ser exaltado é o fim da norma.

Nesse sentido, nos ensina CARRAZA $(2011,865)$ :

Deveras, livro, na acepção do art.150,VI, „de, da $\underline{\mathrm{CF}}$, é o veículo de transmissão do pensamento, pouco importando o processo tecnológico que a realiza (impressão gráfica em papel, impressão magnética em disquete de computador, gravação em fita de vídeo etc)

Corroborando esse raciocínio, afirma MACHADO (2005, p.289) que

\begin{abstract}
A imunidade dos livros, jornais e periódicos tem por fim assegurar a liberdade de expressão do pensamento e a disseminação da cultura. Como é inegável que os meios magnéticos, produtos da moderna tecnologia, são hoje de fundamental importância para realização desse mesmo objetivo, a resposta afirmativa se impõe. O entendimento contrário (...) leva a norma imunizante a uma forma de esclerose precoce, inteiramente incompatível com a doutrina do moderno constitucionalismo.
\end{abstract}

Percebe-se, então, que a interpretação que mais se adequa a hodierna realidade é a que tem o condão de atribuir eficácia mais ampla a regra imunizante, pois ignorar a relevância e a influência da tecnologia negando a equiparação dos livros eletrônicos aos impressos viola os mandamentos constitucionais referentes à liberdade de expressão e a disseminação da cultura.

Até porque, a força normativa do ordenamento está calcada na sua vinculação com o contexto social, com os fatos, motivo pelo qual poderá ocorrer uma frustração material da finalidade dos seus textos, caso não haja uma harmonização com a dinâmica da sociedade.

É o que preceitua Konrad Hesse, na obra a "Força Normativa da Constituição" traduzida por Gilmar Ferreira Mendes (p. 2)

A norma constitucional não tem existência autônoma em face da realidade. A sua essência reside na sua vigência, ou seja, a situação por ela regulada pretende ser concretizada na realidade. Essa pretensão de eficácia (Geltungsanspruch) não pode ser separada das condições históricas de sua realização, que estão, de diferentes formas, numa relação de interdependência, criando regras próprias que não podem ser desconsideradas. Devem ser contempladas aqui as condições naturais, técnicas econômicas, e sociais. A pretensão de eficácia da norma jurídica somente será realizada se levar em conta essas condições.

Revista de Direito Tributário e Financeiro | e-ISSN: 2526 - 0138 | Brasília | v. 2 | n. 1 | p. 1 - 15 | Jan/Jun.2016. 
Desse modo, torna-se imperiosa uma interpretação ampliativa de modo a conferir um tratamento tributário igualitário aos livros eletrônicos e aos seus respectivos suportes magnéticos, pois a nossa Marga Carta deve ser analisada de modo sistemático e uniforme, não podendo o intérprete restringir o alcance da norma constitucional a ponto de contrariar o fundamento da sua própria existência e olvidar da carga axiológica que implicitamente legou o constituinte.

Comunga desse entendimento HARADA (2012, p.77), ao assegurar que:

Essa imunidade outorgada de conformidade com os valores da liberdade, da cultura e da educação não comporta interpretação restritiva ao livro tradicional, pois a nova realidade decorrente da ciência da informática possibilita, igualmente, a transmissão de ideias por vias eletrônicas.

Tanto é assim que, em recente decisão (21/01/2015), entendeu o Tribunal de Justiça do Distrito Federal o seguinte:

CONSTITUCIONAL E TRIBUTÁRIO. AGRAVO DE INSTRUMENTO. MANDADO DE SEGURANÇA. IMUNIDADE DE IMPOSTOS. EREADERS. LIVROS ELETRÔNICOS. EXTENSÃO. INTELIGÊNCIA DO ARTIGO 150, INCISO VI, ALÍNEA „D“, DA CARTA DA REPUBLICA. INTERPRETAÇÃO SISTEMÁTICA E TELEOLÓGICA. VEROSSIMILHANÇA. RECEIO DE À IMPETRANTE/AGRAVADA. RECURSO CONHECIDO E DESPROVIDO. DECISÃO AGRAVADA MANTIDA. 1. "Não e stá e sc ri to, no texto constitucional, que os livros, os iornais e os periódicos só serão imunes quando forem confeccionados de papel. [... ... admitir que só os veículos de papel são imunes e que qualquer outra manifestacão cultural. educacional ou de imprensa seja passível de manipulacão governamental. por tributos, é reduzir a intencão do constituinte a sua expressão nenhuma. Uma tal interpretacão equivalente a considerar que a liberdade de expressão só pode manifesta-se através de veículos de papel!!! - representa, inclusive, um pensamento retrógrado, de retrocesso institucional e intelectual. Significaria considerar que a comunicação social eletrônica pelos meios modernos não merece ser protegida, porque 0 constituinte teria desejado que o País não evoluísse na difusão cultural e na obtenção de informações. [...] Se se admitisse que quem não tem o direito de tributar, pudesse, ,pro domo sua ${ }^{\text {ee }}$, interpretar restritivamente a lei impeditiva, poder-se-iaamesquinhar a intenção do constituinte de afastar da área impositiva aquelas situações e pessoas em atividades consideradas essenciais para a preservação do Estado Democrático de Direito. [...] Com base na Constituição, entendo que são livros aqueles cujo conteúdo seja próprio de um livro, jornal ou periódicos, qualquer que seja a forma de sua veiculação. O que define o livro é o seu conteúdo e não a sua forma. ... perante a Constituição, livro é definido por seu conteúdo e não por sua forma".(MARTINS, Ives Gandra da Silva. Aspectos Referentes a Imunidade dos Livros Eletrônicos... RDDT 180/156, set/2010). 2. Oualquer suporte físico, não importa a aparência que tenha, desde que revele os valores que são imanentes ao livro, é livro, e como livro, estará imune a 
impostos, por forca do art. 150, VI, d, da Constituicão. 3. Evidenciado o preenchimento do requisito do "fumus boni iures" e considerando a iminente importação e comercialização do "e-reader", bem como que a continuidade da cobrança e fiscalização da exação poderá causar lesão à direitos fundamentais tutelados, consubstanciando o "periculum in mora", justificável a providência antecipatória deferida em decisão agravada. Ao reverso, no caso em apreço, não se vislumbra a verossimilhança das alegações do Distrito Federal. Recurso conhecido e desprovido. Decisão agravada mantida. (TJ-DF - AGI: 20140020228830 DF 0023050-98.2014.8.07.0000, Relator: ALFEU MACHADO, Data de Julgamento: 21/01/2015, $3^{\mathrm{a}}$ Turma Cível, Data de Publicação: Publicado no DJE : 28/01/2015 . Pág.: 173) (grifo nosso)

Também decidiu, nesse sentido, o Tribunal regional Federal da $3^{\mathrm{a}}$ Região:

CONSTITUCIONAL. TRIBUTÁRIO. IMUNIDADE. LIVROS ELETRÔNICOS E ACESSÓRIOS. INTERPRETAÇÃO TELEOLÓGICA E EVOLUTIVA. POSSIBILIDADE. 1. Na hipótese dos autos, a imunidade assume a roupagem do tipo objetiva, pois atribui a benesse a determinados bens, considerados relevantes pelo legislador constituinte. 2. 0 preceito prestigia diversos valores, tais como a liberdade de comunicacão e de manifestacão do pensamento: a expressão da atividade intelectual, artística e científica e o acesso e difusão da cultura e da educacão. 3. Conquanto a imunidade tributária constitua excecão à regra jurídica de tributacão, não nos parece razoável atribuir-lhe interpretacão exclusivamente léxica, em detrimento das demais regras de hermenêutica e do "espírito da lei" exprimido no comando constitucional. 4. Hodiernamente, o vocábulo "livro" não se restringe à convencional colecão de folhas de papel, cortadas, dobradas $\mathrm{e}$ unidas em cadernos. 5. Interpretar restritivamente o art. 150, VI, d da Constituição, atendo-se à mera literalidade do texto e olvidando-se da evolução do contexto social em que ela se insere, implicaria inequívoca negativa de vigência ao comando constitucional. 6. A melhor opção é a interpretação teleológica, buscando aferir a real finalidade da norma, de molde a conferir-lhe a máxima efetividade, privilegiando, assim, aqueles valores implicitamente contemplados pelo constituinte. 7. Dentre as modernas técnicas de hermenêutica, também aplicáveis às normas constitucionais, destaca-se a interpretação evolutiva, segundo a qual o intérprete deve adequar a concepção da norma à realidade vivenciada. 8. Os livros são veículos de difusão de informacão, cultura e educacão, independentemente do suporte que ostentem ou da matéria prima utilizada na sua confeccão e como tal, fazem ius à imunidade postulada. Precedente desta E. Corte: Turma Suplementar da Segunda Seção, ED na AC n. ${ }^{\circ}$ 2001.61.00.020336-6, j. 11.10.2007, DJU 05.11.2007, p. 648. 9. A alegação de que a percepção do D. Juízo a quo ingressa no campo político não merece acolhida, haja vista que interpretar um dispositivo legal é exercício de atividade tipicamente jurisdicional. 10. Não há que se falar, de outro lado, em aplicação de analogia para ampliar as hipóteses de imunidade, mas tão-somente da adoção de regras universalmente aceitas de hermenêutica, a fim de alcançar o verdadeiro sentido da norma constitucional. 11. Apelação e remessa oficial improvidas. (TRF-3 - AMS: 5281 SP 2000.61.04.005281-4, Relator: DESEMBARGADORA FEDERAL CONSUELO YOSHIDA, Data de Julgamento: 01/09/2004, SEXTA TURMA) (grifo nosso).

Por todo o exposto, pode-se inferir que, em que pese o entendimento restritivo da nossa Corte Suprema quanto à extensão da imunidade tributária aos livros eletrônicos e 
aos meios magnéticos, vê-se que esse não é o mais coerente e adequado ante a inevitável evolução tecnológica, pois negar essa realidade social seria transformar a nossa Carta Política em um mero documento desprovido de qualquer eficácia social.

\section{CONSIDERAÇÕES FINAIS}

A evolução tecnológica, indubitavelmente, irradia seus efeitos em todos os ramos do ordenamento jurídico. E não poderia ser diferente no âmbito do Direito Tributário, motivo pelo qual se faz necessária a adoção de regras hermenêuticas que tenham o condão de adequar a dinamicidade social as normas constitucionalmente previstas.

A tecnologia fez com que a informação fosse não só transmitida com maior rapidez, mas proporcionou uma evolução no que diz respeito ao armazenamento e acesso aos livros, jornais e outras tantas informações que estão a nossa disposição e que podem ser adquiridas por um simples download.

Isso fez surgir no sistema constitucional tributário um impasse quanto à possibilidade de extensão ou não da regra imunizante, prevista no art. 150, VI, alínea d da Constituição Federal que trata dos livros, jornais, periódicos e o papel destinado a sua impressão, aos livros eletrônicos e aos meios magnéticos.

Há na doutrina divergência quanto à possibilidade de se alargar o sentido e o alcance dessa imunidade. A corrente que adota uma interpretação restritiva entende não ser possível, posto que seria acrescentar um elemento novo na Constituição, devendo então ser aplicada apenas ao papel e a outros insumos similares. Doutra banda, há quem entenda que deve-se realizar uma interpretação extensiva para abarcar também os livros eletrônicos e os insumos diferentes do papel, como os meios magnéticos, pois o que deve ser observado precipuamente é a finalidade da regra imunizante.

A problemática já foi levada a nossa Corte Suprema que, apesar de ter á época reconhecido a repercussão geral, ainda não se debruçou sobre tão relevante tema, motivo pelo qual alguns dos nossos tribunais inferiores, ante a omissão da Corte Maior, tem se manifestado favoravelmente a extensão da regra imunizante.

Assim, percebe-se que faz-se necessária uma quebra de paradigma no que tange ao conceito jurídico de livro, bem como seus insumos, pois independentemente da 
forma como a informação é obtida ou armazenada, a regra imunizante deve incidir, pois leva-se em consideração a finalidade da norma-princípio que é a liberdade de expressão e a disseminação da cultura e não o mero suporte físico.

Portanto, entender que a imunidade tributária é aplicada apenas aos livros impressos e ao suporte físico papel, é enxergar o direito de forma míope, visto que não pode o intérprete, calcado em uma regra interpretativa restritiva, simplesmente se desprender da realidade social e deixar direitos e garantias individuais órfãos de proteção. Assim, não há como efetivar a ideia de cidadania tributária, tal qual propagada no texto constitucional vigente, sem que seja adotada uma interpretação adequada à regra imunizatória em relação aos livros, jornais e periódicos.

\section{REFERÊNCIAS}

BRASIL. Constituição (1988). Constituição da República Federativa do Brasil. Brasília, DF: Senado, 1988.

Lei $\mathbf{n}^{0}$ 10.753, de 30 de outubro de 2003. Institui a Política Nacional do Livro. Diário Oficial da República Federativa do Brasil, Brasília, DF, 31 de outubro de 2003. Disponível em: < http://www.planalto.gov.br/ > Acesso em 28/04/2015.

Supremo Tribunal Federal. Súmula 657, publicada em 09 de outubro de 2003. Disponível em: < http://www.stf.jus.br/portal/jurisprudencia $>$ Acesso em 27/04/2015.

. Supremo Tribunal Federal (Segunda Turma). Recurso Extraordinário $\mathbf{n}^{\mathbf{0}}$ 221.239/ SP. Recorrente: Editora Globo S/A. Recorrido: Estado de São Paulo. Relatora: Ministra Ellen Gracie, Brasília, 25 de maio de 2004. Publicado em 06 de agosto de 2004. Disponível em < http://www.stf.jus.br/ > Acesso em 21/04/2015.

. Supremo Tribunal Federal (Primeira Turma). Recurso Extraordinário no 202.149/ RS. Recorrente: União. Recorrido: Grupo Editorial Sinos S/A. Relator: Ministro Menezes Direito, Brasília, 26 de abril de 2011. Publicado em 11 de outubro de 2011. Disponível em < http://www.stf.jus.br/ > Acesso em 21/04/2015.

.Supremo Tribunal Federal (Decisão monocrática). Embargos de Divergência no Recurso Extraordinário no: 202149/RS. Relator: Ministro Celso de Mello, Brasília, 14 de abril de 2015. Publicado em -16 de abril de 2015. Disponível em

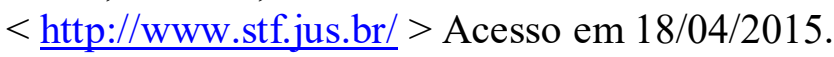

.Supremo Tribunal Federal (Plenário). Repercussão Geral no Recurso Extraordinário no 330.817/RJ. Recorrente: Estado do Rio de Janeiro. Recorrido: Elfez Edição Comércio e Serviços LTDA. Relator: Ministro Dias Toffoli, Brasília, 20 de 
setembro de 2012. Publicado em 01 de outubro de 2012. Disponível em < http://www.stf.jus.br/ > Acesso em 21/04/2015.

.Tribunal de Justiça do Distrito Federal ( $3^{\text {a }}$ Turma Cível). Agravo de Instrumento $\mathrm{n}^{\circ}$ 20140020228830 DF 0023050-98.2014.8.07.0000. Agravante: Distrito Federal. Agravado: Saraiva e Siciliano S/A. Relator: Desembargador Alfeu Machado. Data de Julgamento: 21/01/2015. Publicado no DJE 28/01/2015. Disponível em< $<$ http://tjdf.jusbrasil.com.br/> Acesso em 28/04/2015.

.Tribunal Regional Federal da $3^{\mathrm{a}}$ Região (Sexta Turma) Apelação em Mandado de Segurança no 5281 SP 2000.61.04.005281-4. Apelante: União Federal (Fazenda Nacional). Apelado: Oxford University Press Do Brasil Publicações LTDA. Relator: Desembargadora Federal Consuelo Yoshida. Data de Julgamento: 01/09/2004.

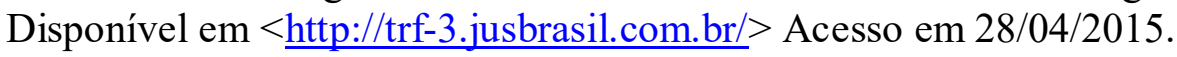

CARRAZA, Roque Antonio. Curso de Direito Constitucional Tributário. 27 ed. São Paulo: Malheiros Editores Ltda., 2011.

COSTA, Regine Helena. Curso de Direito Tributário. Constituição e Código Tributário Nacional. São Paulo: Saraiva, 2009.

GRAU. Eros Roberto. Ensaio e discurso sobre a interpretação/aplicação do direito. São Paulo: Editora Malheiros, 2002.

HARADA, Kiyoshi. Direito Tributário Municipal. Sistema Tributário Municipal.

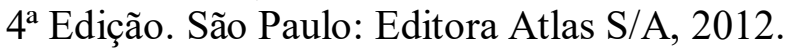

